\title{
Nifedipine versus nitroglycerin for acute tocolysis in preterm labour: a randomised controlled trial
}

\author{
Ajay Dhawle*, Jaswinder Kalra, Rashmi Bagga, Neelam Aggarwal
}

Department of Obstetrics \& Gynecology, Post Graduate Institute of Medical Education \& Research (PGIMER), Chandigarh, India

Received: 8 January 2013

Accepted: 19 January 2013

*Correspondence:

Dr. Ajay S. Dhawle

E-mail: drajaysd@gmail.com

\begin{abstract}
Background: To compare the safety \& efficacy of oral nifedipine with transdermal nitroglycerin in the inhibition of preterm labour.

Methods: This study included 84 women in preterm labour, randomly divided into two groups, 43 receiving oral nifedipine and 41, transdermal nitroglycerin (NTG). Patients in preterm labour with a single gestation, between the 26th and the 34th week and no contraindication for tocolysis were selected. Women with fetal malformation and medical or obstetric diseases were excluded. The variables analyzed were: delay in delivery for 48 hours, 7 days or more than 7 days, period of gestation at delivery, side effect profile of drugs \& neonatal outcomes.

Results: Mean prolongation of pregnancy with NTG (29.04 days) was similar to that of nifedipine (34.46 days). Nifedipine was significantly more successful in prolonging pregnancy beyond 48 hours, especially in women with advanced cervical dilatation $(>3 \mathrm{~cm}$ ). Failure of acute tocolysis, defined as delivery within 48 hours, was significantly more common with NTG (31.7\%) as compared to nifedipine $(11.6 \%)$. Headache was significantly higher in the NTG group $(41.5 \%)$ compared to nifedipine group $(4.7 \%)$. The neonatal outcomes in terms of the mean birth weight, incidence of low birth weight and very low birth weight babies, need and duration of neonatal intensive care was similar in both groups.

Conclusions: Oral nifedipine is a safe and effective tocolytic with a lower failure rate and better side effect profile as compared with transdermal nitroglycerin.
\end{abstract}

Keywords: Preterm labour, Nifedipine, Nitroglycerin, Tocolysis

\section{INTRODUCTION}

Preterm delivery is the leading cause of infant morbidity and mortality in developed countries, accounting for $75 \%$ of perinatal deaths. ${ }^{1}$ Long-term sequelae include chronic lung disease, visual or hearing impairment, developmental delay, and cerebral palsy. ${ }^{2}$ Spontaneous preterm labour is responsible for $40-45 \%$ of all preterm births. ${ }^{3}$ Beta agonists, the commonest agents used for tocolysis, have been associated with numerous sideeffects without actually improving perinatal outcomes. Efforts are therefore being directed towards finding alternatives that are safer, better tolerated as well as efficacious in prolonging pregnancy, thus allowing us time for maternal administration of corticosteroids \& inutero transfer of the babies to units where facilities for neonatal intensive care is available. Both nitroglycerin ${ }^{4-7}$ and nifedipine ${ }^{8-11}$ have been shown to be effective in preterm labour. However, only one study ${ }^{12}$ has directly compared these two tocolytic agents. In our study, we compared the safety and efficacy of oral nifedipine with transdermal nitroglycerin patches as tocolytic in preterm labour.

\section{METHODS}

The study was conducted in the department of Obstetrics \& Gynecology, Post Graduate Institute of Medical Education \& Research (PGIMER), a tertiary care referral centre located in Chandigarh, North India. Women presenting with preterm labour were admitted \& those fulfilling the inclusion were randomized to tocolysis in 
one of the two groups- Group-I: Nitroglycerin (NTG) or Group-II: Nifedipine. The women were subjected to either treatment protocol using computer generated random number table. Preterm labour was defined as presence of regular uterine contractions i.e. 4 in $20 \mathrm{~min}$ or 8 in a period of 1 hour accompanied by any of the following cervical changes- Dilatation $>1 \mathrm{~cm}$ or $/ \&$ Effacement $>80 \%$ or/\& Change in cervical dilatation or effacement observed over 2 hours. The exclusion criteria included any one of the following- hypotension $(80 \mathrm{~mm}$ systolic/ $<50 \mathrm{~mm} \mathrm{Hg}$ diastolic), hypertensive disorders of pregnancy, antepartum hemorrhage, ruptured membranes or signs/symptoms of chorioamnionitis, cervical dilatation $>4 \mathrm{~cm}$, cardiac disease, known tocolytic exposure during current pregnancy, intrauterine fetal demise (IUFD), fetal malformation, severe intrauterine growth restriction (IUGR) \& fetal distress.

Group I Nitroglycerin group: Women were given transdermal nitroglycerin patch, Nitroderm10, which delivers $10 \mathrm{mg}$ NTG over twenty four hours and it was applied to the woman's abdomen. If contractions persisted at the end of one hour an additional patch was applied. No more than 2 patches were worn simultaneously (20 $\mathrm{mg}$ ). At the end of 24 hours these were replaced by a fresh patch. Mild headaches were treated with paracetamol. Patches remained in place for $12 \mathrm{hrs}$ after the contractions had ceased.

Group II Nifedipine group: Tocolysis was initiated with an oral loading dose of nifedipine $20 \mathrm{mg}$. If contractions persisted after 60 minutes, a similar dose was repeated. If labour was suppressed after the first or second dose, a maintenance dose of $20 \mathrm{mg}$ orally every 6 hours was given starting 6 hours following the last dose and continued until 48 hours.

All women were screened for urinary tract infections (UTI)/bacterial vaginosis with a mid-stream clean catch sample \& a high vaginal swab respectively and antibiotic treatment instituted where necessary. All patients received two doses of $12 \mathrm{mg}$ betamethasone intramuscularly, first at admission and a second dose twenty four hours later, in order to accelerate the fetal lung maturity.

Treatment failure: Inability of the drug to prolong gestation for a minimum period of 48 hours or persistence of uterine contractions even after $20 \mathrm{mg}$ of NTG or $40 \mathrm{mg}$ of Nifedipine was considered to be a treatment failure. Under such circumstances, the therapy was discontinued and subsequent management was left to the labour ward team.

The study outcomes were recorded in terms of - Delay in delivery for 48 hours, 7 days and more than 7 days, period of gestation at delivery, onset of subsequent labour- spontaneous or induced, any side effects of each drug \& the neonatal outcomes, recorded as- birth weight, Apgar score, respiratory distress, need and duration of NICU care, neonatal complications and any perinatal mortality. The statistical analysis was performed using the statistical package-SPSS-10. The two groups were analyzed using the Chi-square test and the Student's ttest, as required.

\section{RESULTS}

The study included eighty four women with preterm labour, randomized to Group I: NTG $(n=41)$ and Group II: Nifedipine $(n=43)$ (Table 1$)$. The mean age of women in the two groups were comparable-25.83 \pm 3.87 (years \pm SD) in Group I versus $26.21 \pm 3.99$ years in Group II. There was no significant difference in parity between the two groups, with primigravida women predominating in both groups. Twenty three $(56.1 \%)$ women in Group I were primigravidas and $22(51.2 \%)$ in Group II. History of previous preterm delivery (PTD) was present in only 14 of the 84 women (16.66\%). Six women (14.6\%) in Group I had a previous PTD versus 8 (18.6\%) in Group II, which was comparable. The mean gestational age at the onset of preterm labour was similar in the two groups (31.1 weeks and 31.3 weeks in groups I and II respectively).

Table 1: Comparability of Group I and II with respect to baseline variables amongst the patients.

\begin{tabular}{|c|c|c|c|}
\hline Variables & $\begin{array}{l}\text { Group I } \\
\text { Nitroglycerin }(n=41)\end{array}$ & $\begin{array}{l}\text { Group II } \\
\text { Nifedipine ( } n=43)\end{array}$ & $\begin{array}{l}p \\
\text { value }\end{array}$ \\
\hline Mean Age (years) & $25.83 \pm 3.866$ & $26.21 \pm 3.991$ & 0.659 \\
\hline Primigravidas & $23(56.1 \%)$ & $22(51.2 \%)$ & \multirow{3}{*}{0.734} \\
\hline Para 1 & $13(31.7 \%)$ & $17(39.5 \%)$ & \\
\hline Para 2 or $>$ & $5(12.2 \%)$ & $4(9.3 \%)$ & \\
\hline Previous Preterm delivery & $6(14.6 \%)$ & $8(18.6 \%)$ & 0.625 \\
\hline $\begin{array}{l}\text { Mean gestational age at } \\
\text { presentation (weeks } \pm \text { SD ) }\end{array}$ & $31.10 \pm 2.01$ & $31.30 \pm 1.60$ & 0.439 \\
\hline
\end{tabular}


Table 2: Comparison of prolongation of pregnancy between the two groups.

\begin{tabular}{|lllc|}
\hline $\begin{array}{l}\text { Prolongation of pregnancy } \\
\text { (Days) }\end{array}$ & $\begin{array}{l}\text { Group I } \\
\text { Nitroglycerin }(n=41)\end{array}$ & $\begin{array}{l}\text { Group II } \\
\text { Nifedipine }(\boldsymbol{n}=\mathbf{4 3})\end{array}$ & $\boldsymbol{p}$ value \\
\hline$>2$ & $28(68.3 \%)$ & $38(88.4 \%)$ & 0.0249 \\
\hline$>7$ & $27(65.9 \%)$ & $31(72.1 \%)$ & 0.536 \\
\hline$>21$ & $23(56.2 \%)$ & $22(48.8 \%)$ & 0.650 \\
\hline Mean (days \pm SD) & $29.04 \pm 12.61$ & $34.46 \pm 14.98$ & 0.628 \\
\hline
\end{tabular}

Table 3: Subgroup analysis between the two groups with respect to cervical dilatation at presentation and the mean prolongation of pregnancy.

\begin{tabular}{|l|lll|}
\hline \multicolumn{1}{|c|}{$\begin{array}{c}\text { Cervical dilatation } \\
(\mathbf{c m})\end{array}$} & \multicolumn{2}{|c|}{ Prolongation of pregnancy (days) } & $($ Mean \pm SD) \\
& $\begin{array}{l}\text { Group I } \\
\text { Nitroglycerin }(\boldsymbol{n = 4 1})\end{array}$ & $\begin{array}{l}\text { Group II } \\
\text { Nifedipine }(\boldsymbol{n = 4 3 )}\end{array}$ & Significance \\
\hline$<2$ & $41.40 \pm 18.58$ & $40.04 \pm 20.07$ & $p=0.907$ \\
\hline $2-3$ & $14.08 \pm 11.76$ & $18.50 \pm 11.73$ & $p=0.374$ \\
\hline$>3$ & $0.56 \pm 0.53$ & $5.00 \pm 5.45$ & $p=0.015$ \\
\hline
\end{tabular}

Table 4: Neonatal outcomes in the two groups.

\begin{tabular}{|llll|}
\hline Neonatal outcomes & $\begin{array}{l}\text { Group I } \\
\text { Nitroglycerin }(n=41)\end{array}$ & $\begin{array}{l}\text { Group II } \\
\text { Nifedipine }(n=43)\end{array}$ & $p$ value \\
\hline Birth weight $<2.5 \mathrm{~kg}$ & $27(65.9 \%)$ & $26(60.5 \%)$ & 0.684 \\
\hline Birth asphyxia & $4(9.8 \%)$ & $5(11.6 \%)$ & 0.782 \\
\hline Neonatal jaundice & $20(48.8 \%)$ & $21(48.8 \%)$ & 0.996 \\
\hline RDS & $7(17.1 \%)$ & $4(9.3 \%)$ & 0.291 \\
\hline Hypoglycemia & $3(7.3 \%)$ & $1(2.3 \%)$ & 0.283 \\
\hline Sepsis & $1(2.4 \%)$ & $1(2.3 \%)$ & 0.973 \\
\hline Others & $3(7.3 \%)$ & $2(4.7 \%)$ & 0.606 \\
\hline NICU care & $4(9.8 \%)$ & $5(11.6 \%)$ & 0.782 \\
Mean duration & $13 \pm 6.377$ & $14.2 \pm 10.964$ & 0.853 \\
\hline
\end{tabular}

Table 5: Comparison of side-effect profile between the two groups.

\begin{tabular}{|llll|}
\hline Side Effects & $\begin{array}{l}\text { Group I } \\
\text { Nitroglycerin }(\boldsymbol{n}=\mathbf{4 1})\end{array}$ & $\begin{array}{l}\text { Group II } \\
\text { Nifedipine }(\boldsymbol{n}=\mathbf{4 3})\end{array}$ & $\boldsymbol{p}$ value \\
\hline Palpitations & $3(7.3 \%)$ & $4(9.3 \%)$ & 0.742 \\
\hline Headache & $17(41.5 \%)$ & $2(4.7 \%)$ & 0.001 \\
\hline Tachycardia & $8(19.5 \%)$ & $11(25.6 \%)$ & 0.506 \\
\hline Hypotension & $0(0.00 \%)$ & $2(4.7 \%)$ & 0.162 \\
\hline $\begin{array}{l}\text { Treatment } \\
\text { discontinuation }\end{array}$ & $1(2.4 \%)$ & $4(9.3 \%)$ & 0.386 \\
\hline
\end{tabular}

The mean prolongation of pregnancy was $29.04 \pm 12.61$ days in Group I versus $34.46 \pm 14.98$ days in Group II, which was not statistically significant. However, failure of acute tocolysis, defined as delivery within 48 hours, was significantly more with NTG (13/41 women-31.7\%) 
as compared to Nifedipine (5/43 women-11.6\%) (Table 2). In the NTG group, 21 women $(51.2 \%)$ delivered after 34 weeks of gestation and $9(22.0 \%)$ after 37 weeks as compared to $28(65 \%)$ after 34 weeks and $13(30.2 \%)$ after 37 weeks of gestation in nifedipine group. This however did not reach statistically significant proportions. Also the mean gestational age at delivery was similar in both groups- $34.59 \pm 2.79$ weeks in NTG group as against $35.09 \pm 2.84$ weeks in nifedipine group.

Cervical dilatation at the onset of tocolysis was the most important factor influencing prolongation of pregnancy. In the NTG group, 19 of the 20 women $(95 \%)$ presenting with a dilatation of $<2 \mathrm{~cm}$ had a pregnancy prolongation of atleast 21 days. This was in stark contrast to the observation that none of the 9 women who presented with dilation of $>3 \mathrm{~cm}$ could be prolonged beyond 48 hours and were labeled treatment failures. Even in the nifedipine group, 18 of the 21 women $(85.71 \%)$ presenting with a dilatation of $<2 \mathrm{~cm}$ had a pregnancy prolongation beyond 3 weeks, whereas in those with a dilatation of $>3 \mathrm{~cm}$ at onset of tocolysis, 3 out of 8 $(37.5 \%)$ women delivered within 48 hours. Comparing the two groups with respect to both cervical dilatation at onset of tocolysis and the mean prolongation of pregnancy, when the cervical dilatation was $<3 \mathrm{~cm}$, there was no significant difference between the two groups (Table 3). However when the cervical dilatation was $>3 \mathrm{~cm}$, nifedipine was significantly more effective in prolonging pregnancy compared to NTG $(5.00 \pm 5.45$ days versus $0.56 \pm 0.53$ days; $p=0.015$ ).

The two groups performed similarly with respect to the mean birth weights, incidence of low birth weight (LBW), very low birth weight (VLBW) babies and the mode of delivery. Similarly there was no significant difference in the neonatal outcomes (Table 4) \& complications like respiratory distress syndrome (RDS), birth asphyxia, hypoglycemia, sepsis, need for neonatal intensive care unit (NICU) admission and mean duration of stay. Neonatal Jaundice was the commonest complication $41 / 84$ women $(48.8 \%)$ followed by RDS 11/84 (13.09\%).

Among maternal side-effects (Table 5), headache was significantly higher in the NTG group compared to nifedipine group $(17 / 43,41.5 \%$ versus $2 / 41,4.7 \%, p=$ $0.001)$. Hypotension was exclusively seen with nifedipine (2 women- $4.7 \%$ ). However, the incidence of other maternal complications was not significantly different in the two groups. More number of women required discontinuation of treatment with nifedipine (4/43, 9.30 $\%)$ compared to nitroglycerin $(1 / 41,2.43 \%)$. However statistical difference could not be established.

\section{DISCUSSION}

Prolongation of pregnancy beyond 48 hours allows the beneficial effect of corticosteroids on fetal lung maturity to come into play. Lees et $\mathrm{al}^{4}$ found that NTG prolonged gestation beyond 2 days in $84 \%$ patients compared with $88 \%$ in the ritodrine group. Wani et $\mathrm{al}^{5}$ found the prolongation beyond 2 days to be $91 \%$ with NTG versus $88 \%$ in ritodrine group. In the RNOTT multicentric trial, ${ }^{7}$ however, NTG showed a lower (63\%) efficacy in prolonging labour beyond 48 hours against $71 \%$ with ritodrine. Nifedipine prolonged pregnancy beyond two days in $80.9 \%$ women compared to $69.5 \%$ in ritodrine in a study by Papatsonis et al, ${ }^{8}$ whereas, Kashanian et $\mathrm{al}^{9}$ found the pregnancy prolongation beyond two days to be $75 \%$ in nifedipine group versus $82.5 \%$ with atosiban group. A direct comparison of NTG with nifedipine by Amorim et $\mathrm{al}^{12}$ showed that the rate of preterm delivery within 48 hours after start of tocolysis was $15.4 \%$ in tocolysis with NTG and $12.5 \%$ in the nifedipine group. In the present study, nifedipine was significantly better in pregnancy prolongation beyond 48 hours $(88.4 \%$ women in nifedipine group versus $68.3 \%$ in the NTG group).

Wani et $\mathrm{al}^{5}$ found NTG to delay delivery beyond 7 days and 14 days in $87 \% \& 85 \%$ of patients respectively compared to $73 \%$ \& $69 \%$ in ritodrine group, where as Lees et $\mathrm{al}^{4}$ found the same to be $77 \%$ \& $73 \%$ for NTG versus $81 \% \& 78 \%$ for ritodrine. The RNOTT trial $^{7}$ found pregnancy prolongation of more than 7 days in $53 \%$ in the NTG group as against 59\% in ritodrine group. In the trial by Papatsonis et al, ${ }^{8}$ nifedipine was found to delay childbirth beyond $7 \& 14$ days in $72.1 \%$ and $64.7 \%$ patients respectively, compared to $50 \%$ and $40.7 \%$ prolongation in the ritodrine group. Kashanian et $\mathrm{al}^{9}$ found pregnancy prolongation beyond 7 days in $65 \%$ in nifedipine group versus $74 \%$ in atosiban group. In the present study, nifedipine delayed delivery beyond $7 \& 14$ days in $72.1 \%$ and $62.8 \%$ respectively which was not significantly different to that seen with NTG $(65.9 \%$ \& $58.6 \%$ respectively). The mean pregnancy prolongation in the present study was 29.04 days in the NTG group against 34.46 days in the nifedipine group, which was similar to the results of Papatsonis et $\mathrm{al}^{9}$ (39.2 days with nifedipine versus $22.1 \%$ with ritodrine) \& Lees et $\mathrm{al}^{4}$ (35.8 days with NTG versus 36.9 days with ritodrine).

We have also analyzed the prolongation of pregnancy with respect to the cervical dilatation at presentation. When the dilatation was $<2 \mathrm{~cm}$ the mean prolongation in NTG group was 41.4 days, compared to 40.04 days in nifedipine group. Amongst those who presented with initial cervical dilatation $2-3 \mathrm{~cm}$, the mean pregnancy prolongation was 14.08 days with NTG versus 18.5 days with nifedipine, which again was statistically non significant. However, at a cervical dilatation of $>3 \mathrm{~cm}$, the mean pregnancy prolongation was only 0.56 days with NTG compared to 5 days with nifedipine, which was statistically significant $(p=0.015)$. Moreover, at more than $3 \mathrm{~cm}$ dilatation, nifedipine prolonged pregnancy beyond 48 hours in $62.5 \%$ patients against none with NTG. Bisits et $\mathrm{al}^{7}$ found that after 2 hours of therapy, significantly more $(77 \%)$ women had no or only mild contractions against $43 \%$ in those receiving transdermal nitrates. This slower onset of action may have resulted in poorer 
outcomes, especially in women with greater cervical dilatation at presentation.

A number of studies ${ }^{13-15}$ have quoted that nifedipine decreases the incidence of RDS, similarly, Smith et al, ${ }^{16}$ reported that fewer neonates in the NTG group suffered RDS compared to placebo, although no conclusion could be drawn in view of small sample size. In the present study, the mean birth weights in the two groups were 2.11 $\mathrm{kg}$ (NTG) and $2.14 \mathrm{~kg}$ (nifedipine). The distribution of the LBW \& VLBW babies was also similar in the two groups. The incidence of RDS was $17.1 \%$ in NTG group and $9.3 \%$ in the nifedipine group and the difference was statistically not significant. Neonatal jaundice was the most common complication in the present study, $(48.8 \%$ of neonates from either group). This was because majorities $(75 \%)$ of the babies in this study were born preterm at less than 37 weeks of gestation. There were three neonatal deaths in extremely LBW neonates, all in the NTG group, although this was not statistically significant.

Lees et $\mathrm{al}^{4}$ compared the side effects of NTG and ritodrine \& found that the only side effect with NTG was headache, which was more common when two patches were worn simultaneously. Bisits et $\mathrm{al}^{7}$ found similar results. Wani et $\mathrm{al}^{5}$ observed the incidence of headache to be $25 \%$ and total incidence of side effects with NTG to be $30 \%$. Papatsonis et $\mathrm{al}^{8}$ found the incidence of side effects with nifedipine to be significantly less when compared to ritodrine (18.9\% versus $36 \%$ ). Kashanian et $\mathrm{al}^{9}$ found that nifedipine was associated with side effects in $40 \%$ of patients as compared to $17.5 \%$ with atosiban. They also found the incidence of hypotension with nifedipine to be $27.7 \%$. In the present study, the total incidence of side effects was $48.7 \%$ with NTG against $34.88 \%$ with nifedipine. Headache was significantly more associated with NTG (41.5\% versus $4.7 \%)$. There was no difference in the incidence of tachycardia or palpitations amongst the two groups. However two women in the nifedipine group did develop clinically significant hypotension \& tachycardia requiring treatment discontinuation. Four women $(9.3 \%)$ in the nifedipine group required treatment discontinuation compared to a single woman $(2.43 \%)$ in the NTG group, which, however, was not statistically significant.

In conclusion, the results of this study demonstrate that oral nifedipine is more effective than transdermal NTG in prolonging pregnancy beyond 48 hours, especially in women with cervical dilatation of $>3 \mathrm{~cm}$. Failure of tocolysis was more common with the NTG patch as was headache. The neonatal outcomes and other side effects were comparable between the two groups. However further studies with greater number of subjects and ones where either cervical length measurement using transvaginal sonography or fetal fibronectin are incorporated into the definition of preterm labour need to be done to arrive at a final conclusion.
Funding: No funding sources

Competing interests: There are no competing interests to declare

Ethical approval: The study was approved by the institutional ethics committee

\section{REFERENCES}

1. Demissie K, Rhoads GG, Ananth CV, et al. Trends in preterm birth and neonatal mortality among blacks and whites in the United States from 1989 to 1997. Am J Epidemiol 2001;154:307-15.

2. Hack M, Taylor HG, Klein N, et al. School-age outcomes in children with birth weight under $750 \mathrm{~g}$. N Engl J Med 1994;331:753-9.

3. Goldenberg RL, Rouse DJ. Prevention of premature birth. N Engl J Med 1998;339:313-20.

4. Lees CC, Lojacono A, Thompson C, Danti L, Black RS, Tanzi P, White IR, Campbell S. Glyceryl trinitrate and ritodrine in tocolysis: an international multicenter randomized study. GTN Preterm Labour Investigation Group. Obstet Gynecol 1999;94:403-8.

5. Wani MP, Barakzai N, Graham I. Glyceryl trinitrate vs ritodrine for the treatment of preterm labour. Int $\mathbf{J}$ Gynecol Obstet 2004;85:165-7.

6. Schleussner E, Möller A, Gross W, et al. Maternal and fetal side effects of tocolysis using transdermal nitroglycerin or intravenous fenoterol combined with magnesium sulfate. Eur J Obstet Gynecol Reprod Biol 2003;106:14-9.

7. Bisits A, Madsen G, Knox M, et al. The Randomized Nitric Oxide Tocolysis Trial (RNOTT) for the treatment of preterm labor. Am J Obstet Gynecol 2004;191:683-90.

8. Papatsonis DN, Van Geijn HP, Adèr HJ, Lange FM, Bleker OP, Dekker GA. Nifedipine and ritodrine in the management of preterm labor: a randomized multicenter trial. Obstet Gynecol 1997;90:230-4.

9. Kashanian M, Akbarian AR, Soltanzadeh M. Atosiban \& nifedipine for the treatment of preterm labour. Int J Gynecol Obsyet 2005;91:10-14.

10. King JF, Flenady VJ, Papatsonis DN, Dekker GA, Carbonne B. Calcium channel blockers for inhibiting preterm labour. Cochrane Database Syst Rev 2003;(1):CD002255.

11. Conde-Agudelo A, Romero R, Kusanovic JP. Nifedipine in the management of preterm labor: a systematic review and metaanalysis. Am J Obstet Gynecol 2011;204:134.e1-20.

12. Amorim MM, Lippo LA, Costa AA, Coutinho IC, Souza AS. Transdermal nitroglycerin versus oral nifedipine administration for tocolysis: a randomized clinical trial. Rev Bras Ginecol Obstet 2009;31:5528.

13. Tsatsaris V, Papatsonis D, Guffinet F, Dekker G, Carbonne B. Tocolysis with nifedipine or beta adrenergic agonists: a meta analysis. Obstet Gynecol 2001;97:840-7.

14. King J, Flenady V, Papatsonis DM, Dekker GA, Carbonne S. Calcium channel blockers for inhibiting 
preterm labour: a systematic review of the evidence $\&$ a protocol for administration of nifedipine. Aust NZ J Obstet Gynecol 2003;43:192-8.

15. Oei SG. Calcium channel blockers for tocolysis. A reviewing of their role \& safety following reports of serious adverse events. Eur J Obstet Gynecol Reprod Biol 2006;126:137-45.
16. Smith NG, Walker MC, McGrath MJ. Randomised double blind, placebo comtrolled pilot study assessing nitroglycerin as a tocolytic. $\mathrm{Br} \mathrm{J}$ Obstet Gynecol 1999;106:736-9.

DOI: $10.5455 / 2320-1770.1 j \mathrm{rcog} 20130211$

Cite this article as: Dhawle A, Kalra J, Bagga R, Aggarwal N. Nifedipine versus nitroglycerin for acute tocolysis in preterm labour: a randomised controlled trial. Int $\mathbf{J}$ Reprod Contracept Obstet Gynecol 2013;2:61-6. 